\title{
Assessing Knowledge, Attitudes and Practices of dental practitioners regarding the COVID-19 pandemic: A multinational study
}

\section{Ocena wiedzy, zachowań i działań praktycznych u lekarzy dentystów w związku z pandemią COVID-19 - wielonarodowe badanie ankietowe} \author{
Ahmed Jhurry Hadi $3, B, D, E$, Alankrita Chaudhary ${ }^{2}, B, F$, Ruby Joshi ${ }^{4, B, E}$, Kuldeep Dhanker ${ }^{2, B, C, F}$ \\ 1 Department of Public Health Dentistry, Institute of Dental Sciences (IDS), Bareilly, India \\ ${ }^{2}$ Department of Public Health Dentistry, School of Dental Sciences, Sharda University, Greater Noida, India \\ ${ }^{3}$ Private Practice, Port Louis, Mauritius \\ ${ }^{4}$ Private Practice, Katmandu, Nepal \\ A - research concept and design; $B$ - collection and/or assembly of data; $C$ - data analysis and interpretation; \\ $D$ - writing the article; $E$ - critical revision of the article; $F$ - final approval of the article
}

Shivalingesh Krishnappa Kamate ${ }^{1, A, B, E, F}$, Swati Sharma ${ }^{2, A, C, E}$, Sahil Thakar ${ }^{2, B, D}$, Divya Srivastava ${ }^{1, A, C, E}$, Kaushikee Sengupta ${ }^{2, B, C}$,

Address for correspondence

Shivalingesh Krishnappa Kamate

E-mail: shivgesh@gmail.com

Funding sources

None declared

Conflict of interest

None declared

Received on March 17, 2020

Reviewed on March 25, 2020

Accepted on March 26, 2020

Published online on March 31, 2020

Cite as

Kamate SK, Sharma S, Thakar S, et al. Assessing Knowledge, Attitudes and Practices of dental practitioners regarding the COVID-19 pandemic: A multinational study. Dent Med Probl. 2020;57(1):11-17. doi:10.17219/dmp/119743

DOI

$10.17219 / \mathrm{dmp} / 119743$

Copyright

( 2020 by Wroclaw Medical University

This is an article distributed under the terms of the

Creative Commons Attribution 3.0 Unported License (CC BY 3.0)

(https://creativecommons.org/licenses/by/3.0/)

\section{Abstract}

Background. Coronavirus Disease 2019 (COVID-19) has been declared a global public health emergency that is affecting people across the globe.

Objectives. The aim of this study was to assess the Knowledge, Attitudes and Practices (KAP) of dental practitioners regarding the Coronavirus Disease 2019 (COVID-2019) pandemic.

Material and methods. An online questionnaire was distributed among dentists across the globe using a combination of convenience and snowball sampling. The questionnaire was divided into 4 sections: the $1^{\text {st }}$ one contained personal information, whereas the $2^{\text {nd }}, 3^{\text {rd }}$ and $4^{\text {th }}$ sections assessed knowledge (11 questions), attitudes (6 questions) and practices (7 questions) of the dentists. The data was subjected to the Shapiro-Wilk test, one-way analysis of variance (ANOVA), multivariate linear regression, and Pearson's correlation; $95 \%$ confidence interval (Cl) was calculated and odds ratio (OR) was obtained. The analysis was done using IBM SPSS for Windows, v. 21.0.

Results. The total number of the responses received (860) was divided with regard to various continents (Asia, Americas - North and South, Europe, Africa, and other - Australia and Antarctica). The largest number of dentists came from the Asian continent (264; 30.7\%). Most dentists had a degree of MDS (Master of Dental Science) (301; 35.0\%), followed by BDS (Bachelor of Dental Surgery) (282; 32.8\%) and DDS (Doctor of Dental Surgery) (226; 26.3\%). High/Good knowledge and practice scores were observed among $92.7 \%$ and $79.5 \%$ of the dentists, respectively. Good knowledge scores were significantly associated with qualifications $(p=0.04)$ and years of practice $(p=0.02)$; good practice scores were associated with qualifications only $(p=0.03)$.

Conclusions. The dentists were found to have good knowledge and practice scores, which is important to combat COVID-19. They are advised to follow the Centers of Disease Control and Prevention (CDC) and World Health Organization (WHO) guidelines in their clinics, and sensitize their staff so that no stone is left unturned in defeating this pandemic.

Key words: dentists, COVID-19, pandemic

Słowa kluczowe: dentyści, COVID-19, pandemia 


\section{Introduction}

At the dawn of a new decade, on $30^{\text {th }}$ January, 2019, the World Health Organization (WHO) declared a global public health emergency against the outbreak of coronavirus disease, which is termed as Coronavirus Disease 2019 (COVID-19), and since then has rapidly achieved a pandemic status. This disease with flu-like symptoms was initially observed among people residing in Wuhan, Hubei Province in China. ${ }^{1}$

The causative organism responsible for this outbreak - the Severe Acute Respiratory Syndrome Coronavirus 2 (SARS-CoV-2) - belongs to the family Coronaviridae of the order Nidovirales. This virus structurally comprises of a large, single, plus-stranded RNA as its genome. ${ }^{2,3}$ A total of 4 genera of coronaviruses have been discovered to date and these are: $\alpha-\mathrm{CoV}, \beta-\mathrm{CoV}, \gamma-\mathrm{CoV}$, and $\delta-\mathrm{CoV}$. The $\alpha-\mathrm{CoV}$ and $\beta-\mathrm{CoV}$ variants are observed to infect mainly the respiratory, gastrointestinal and central nervous system of humans and/or mammals, whereas $\gamma-\mathrm{CoV}$ and $\delta$-CoV have been reported with reference to the infections limited to bird species. ${ }^{5}$

Humans suffering from this disease clinically present with the primary symptoms of fever, cough, myalgia or fatigue, abnormal chest computed tomography (CT) image, and severe respiratory distress, whereas less common symptoms include sputum production, headache, hemoptysis, and diarrhea. ${ }^{3,6,7}$ Initially, it was considered to have a zoonotic route of transmission; however, a new person-to-person route of transmission is causing the disease to spread rapidly across different continents and is more likely to affect elderly males. ${ }^{3,8}$

Environmental contamination has been singled out as the primary factor for the nosocomial spread of the newest strains of viruses. ${ }^{9,10}$ With regard to SARS-CoV-2, researchers have confirmed its nosocomial transmission, although very little is known about its mode of transmission and the extent of environmental contamination. ${ }^{11}$ In a dental setting, as the dentist and their equipment are in close proximity to the patient, the chance of acquiring infection from the micro-droplets of an infected patient is high and there is a risk of cross-transmission, too.

In developing and tourist-friendly countries, there is a boom of dental tourism due to the availability of quality treatment at affordable prices, which attracts patients from all over the world. ${ }^{12}$ In the event of an outbreak, the dentist can be the first person to come in contact with an infected person; they can either unknowingly become a carrier and infect others or by following proper guidelines can prevent the possible spread of the disease and save the entire community from its disastrous consequences. Dentists who specialize in the field of public health dentistry are at an increased risk of contacting such an infection due to the nature of their work, which involves promoting oral health among their communities with limited resources.
To combat an outbreak, dentists should be aware of recent developments, especially those related to public health, and by following apt guidelines (i.e., the WHO guidelines at https:/www.who.int/emergencies/diseases/ novel-coronavirus-2019/technical-guidance) make efforts to prevent the transmission of such diseases. Hence, the present study was undertaken with the aim to assess the Knowledge, Attitudes and Practices (KAP) of dental practitioners regarding the COVID-2019 pandemic.

\section{Material and methods}

Prior to the implementation of this KAP study, the questionnaire design, validation, pilot study, and strategies to enroll dentists for maximal global participation were discussed. This study was approved by the Institutional Ethics Committee of the Institute of Dental Sciences (IDS) in Bareilly, India (No. IEC/57/2019). The main instrument to collect data was an online questionnaire using Google forms and it is available at: https://forms.gle/5sgxWngughJg23K46. Upon clicking on the link, the $1^{\text {st }}$ page assured the confidentiality of data, informed the dentists of the study objectives and stated that the study participation was purely voluntary. The dentists' consent to participate in the study (inclusion criteria) was implied when they clicked on the 'next' button to answer the questionnaire, and they had complete freedom either to decline or answer the questionnaire. Only the principal investigator had access to the data and no personal details (e-mail address, phone number, name, etc.) were required. Responses were sought from only those dentists who at least had completed their graduation in dentistry and a submission was considered only when the 'submit' button was clicked at the end of the questionnaire (inclusion criteria). Among total submissions, if a dentist failed to answer $\geq 1$ question, it was excluded from the analysis (Fig. 1).

The study duration was from $25^{\text {th }}$ December, 2019 to $20^{\text {th }}$ February, 2020, and both convenience sampling (researchers themselves contacted dentists to participate in the study) and snowball sampling (the participating dentists were asked to forward the questionnaire to their colleagues) were used so that maximal participation could be ensured. The questionnaire was distributed personally via a quick response (QR) code as well as posted on various social media platforms like Facebook and WhatsApp. The questionnaire was divided into 4 sections and had a total of 24 questions. The $1^{\text {st }}$ section contained personal information (continent of residence, highest qualification, currently practicing as (an academician, clinician, or both), and years of practice), whereas the $2^{\text {nd }}, 3^{\text {rd }}$ and $4^{\text {th }}$ sections assessed the knowledge (11 questions), attitudes (6 questions) and practices (7 questions) of the dentists regarding COVID-19. A pilot study was done on 25 dentists to validate the questionnaire and its Cronbach's alpha $(\alpha)$ was found to be 0.79 . The pilot study responses and incomplete responses were excluded from the main analysis. 


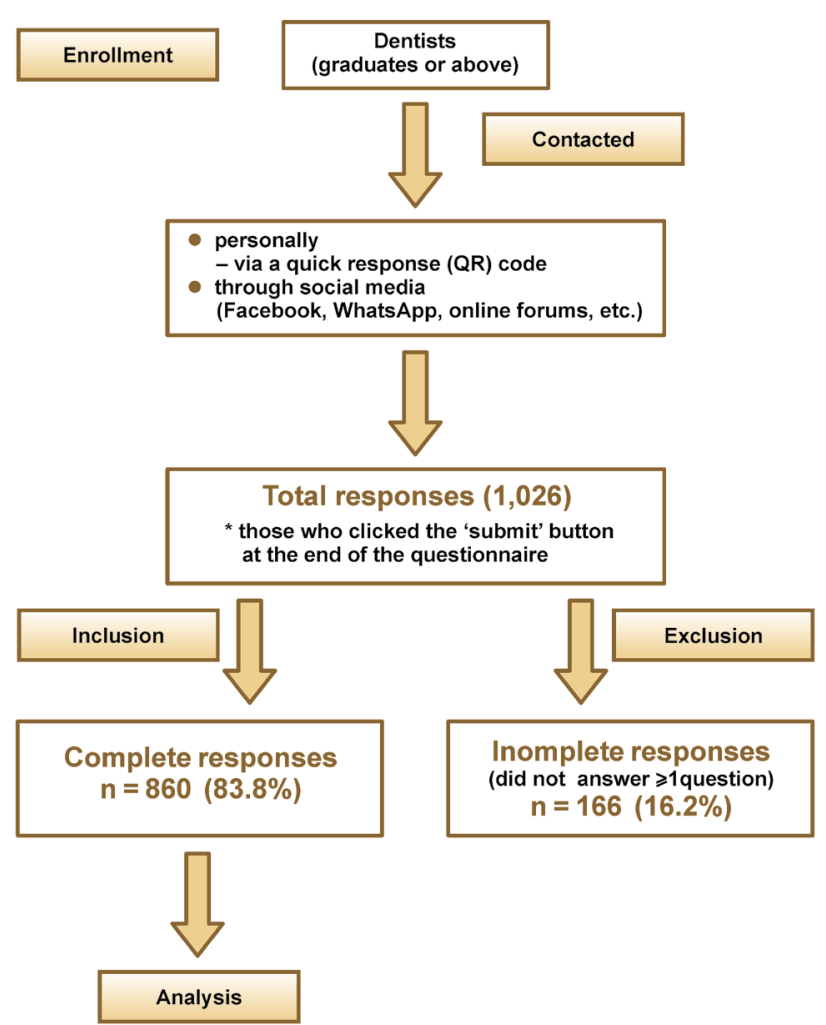

Fig. 1. Study protocol

The data analysis included the Shapiro-Wilk test (to check the data for normality), one-way analysis of variance (ANOVA), multivariate linear regression, and Pearson's correlation coefficient; 95\% confidence interval (CI) was calculated and odds ratio (OR) was obtained. The coded data was sent to the statistician so that the confidentially of the data could be maintained. The analysis was done using IBM SPSS for Windows, v. 21.0 (IBM Corp., Armonk, USA). ${ }^{13}$

\section{Results}

A total of 1,026 submissions were recorded, among which 860 were complete responses and were included in the analysis (response rate: $83.8 \%$ ).

\section{Socio-demographic characteristics of the participating dentists}

Since the present study adopted a global approach, the total number of the responses received (860) was divided with regard to various continents (Asia, Americas - North and South, Europe, Africa, and other - Australia and Antarctica), with the largest number of dentists coming from the Asian continent (30.7\%) and the fewest responses from 'other' continents (5.4\%). Most dentists had a degree of MDS (Master of Dental Science) (35.0\%), followed by BDS (Bachelor of Dental Surgery)
(32.8\%) and DDS (Doctor of Dental Surgery) (26.3\%). The majority of them were clinicians (65.0\%) and an experience period of 2-5 years was mostly reported (34.5\%) (Table 1).

\section{Responses to the questionnaire and the source of information regarding COVID-19}

The source of information regarding COVID-19 was primarily the Internet $(37.7 \%)$, followed by social media sites (30.9\%), television (20\%), newspapers (10\%), and other (1.4\%) (Table 2).

\section{Knowledge regarding COVID-19}

Almost all (99.4\%) of the dentists heard about the coronavirus, whereas only $90.9 \%$ could name it correctly. A total of $98.4 \%$ of the dentists could identify the epicentre; $68.1 \%$ and $64.2 \%$ of the dentists, respectively, knew about vaccine availability and the method of diagnosing the disease. A total of $95.9 \%$ of the dentists believed that COVID-19 was fatal in nature and $99.8 \%$ reported that wearing mouth masks could prevent its transmission. Significant differences were observed when the dentists responded to questions regarding the affected system $(p=0.011)$ and the fatality of COVID-19 $(p=0.023)$ (Table 2).

Table 1. Sociodemographic characteristics of the participating dentists

\begin{tabular}{|c|c|c|}
\hline & Characteristic & n (\%) \\
\hline \multirow{5}{*}{$\begin{array}{l}\text { Continent } \\
\text { of residence }\end{array}$} & Asia & $264(30.7)$ \\
\hline & Americas (North and South) & $215(25.0)$ \\
\hline & Europe & $140(16.3)$ \\
\hline & Africa & 194 (22.6) \\
\hline & other (Australia and Antarctica) & $47(5.4)$ \\
\hline \multirow{6}{*}{$\begin{array}{l}\text { Highest } \\
\text { qualification }\end{array}$} & $\mathrm{PhD}$ & $14(1.6)$ \\
\hline & MDS & $301(35.0)$ \\
\hline & DDS & $226(26.3)$ \\
\hline & DMD & $37(4.3)$ \\
\hline & BDS & $282(32.8)$ \\
\hline & other & - \\
\hline \multirow{3}{*}{$\begin{array}{l}\text { Currently } \\
\text { practicing as }\end{array}$} & an academician & $202(23.5)$ \\
\hline & a clinician & $559(65.0)$ \\
\hline & both & 99 (11.5) \\
\hline \multirow{5}{*}{$\begin{array}{l}\text { Years } \\
\text { of practice }\end{array}$} & $0-2$ & $216(25.1)$ \\
\hline & $2-5$ & $297(34.5)$ \\
\hline & $5-10$ & $199(23.1)$ \\
\hline & $>10$ & $45(5.3)$ \\
\hline & currently not practicing & $103(12.0)$ \\
\hline
\end{tabular}

PhD - Doctor of Philosophy; MDS - Master of Dental Science;

DDS - Doctor of Dental Surgery; DMD - Doctor of Dental Medicine; BDS - Bachelor of Dental Surgery.

Percentages rounded off to the nearest decimal. 
Table 2. Responses to the questionnaire by the participating dentists

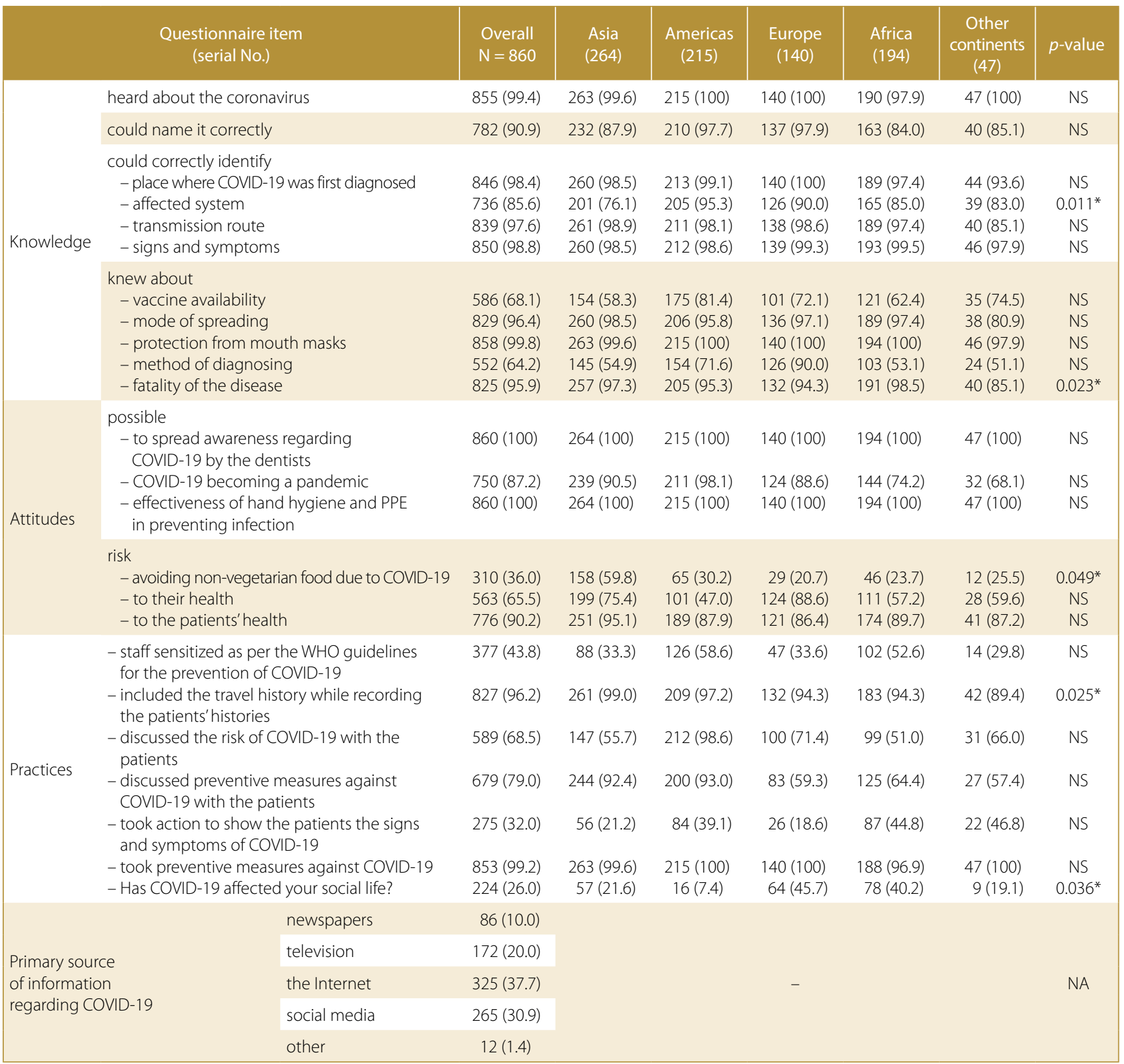

COVID-19 - Coronavirus Disease 2019; PPE - personal protective equipment; WHO - World Health Organization; NS - nonsignificant; NA - not applicable; * statistically significant $(p<0.05)$.

Data presented as number (percentage); percentages rounded off to the nearest decimal.

\section{Attitudes regarding COVID-19}

All dentists (100\%) agreed that it was possible for dentists to spread awareness regarding COVID-19, and that hand hygiene and personal protective equipment (PPE) were highly effective in preventing infection. A total of $87.2 \%$ of the dentists believed that COVID-19 could achieve a pandemic status; $65.5 \%$ responded that it was a risk to their own health, whereas $90.2 \%$ believed that it was a risk to their patients' health. Non-vegetarian food was being avoided by $36 \%$ of the dentists and the difference was found to be statistically significant $(p=0.049)$ (Table 2).

\section{Practices regarding COVID-19}

At the time of responding to the questionnaire, only $43.8 \%$ of the dentists had sensitized their staff as per the WHO guidelines for the prevention of COVID-19 in their workplace. Discussion regarding the risk of COVID-19 
and preventive measures to be taken among their patients was reported by $68.5 \%$ and $79.0 \%$ of the dentists, respectively. A total of $32.0 \%$ of dentists took some kind of action to show their patients the signs and symptoms of the disease, whereas $99.2 \%$ took preventive measures against COVID-19. As many as $96.2 \%$ of the dentists admitted to including the travel history while recording the case history of the patient $(p=0.025)$, whereas $26 \%$ of them responded that COVID-19 had an effect on their social life $(p=0.036)$ (Table 2).

\section{Knowledge and practice scores of the participating dentists}

Based on the median of the scores obtained, the cut-off points for the knowledge (maximum score 13) and practice (maximum score 7) scores were 8 and 4 respectively. No dentist achieved a prefect knowledge score (range: 5-12),

Table 3. Knowledge and practice scores of the participants regarding Coronavirus Disease 2019 (COVID-19)

\begin{tabular}{|c|c|c|}
\hline & Characteristic & Value \\
\hline & range of scores achieved (maximum 13) & $5-12$ \\
\hline & mean $\pm S D$ & $8.1 \pm 2.5$ \\
\hline Knowledge & median (cut-off point) & 8 \\
\hline & high/good knowledge scores n (\%) & $797(92.7)$ \\
\hline & low/poor knowledge scores n (\%) & $63(7.3)$ \\
\hline & range of scores achieved (maximum 7) & $1-7$ \\
\hline & mean $\pm S D$ & $4.1 \pm 2.5$ \\
\hline Practice & median (cut-off point) & 4 \\
\hline & high/good practice scores n (\%) & $684(79.5)$ \\
\hline & low/poor practice scores n (\%) & $176(20.5)$ \\
\hline
\end{tabular}

SD - standard deviation. but perfect scores were observed in the practice section of the questionnaire (range 1-7). High/Good knowledge and practice scores were seen in $92.7 \%$ and $79.5 \%$ of the participating dentists, respectively (Table 3 ).

\section{Association between demographic variables and knowledge and practice scores}

The multiple linear regression model to analyze the knowledge and practice scores in relation to demographic variables revealed that good knowledge scores were significantly associated with qualifications $(p=0.04)$ and the years of practice $(p=0.02)$, whereas good practice scores were associated with qualifications only $(p=0.03)$ (Table 4).

\section{Relationship between knowledge and practice scores}

A positive, linear, great strength of association $(\mathrm{r}:+0.669)$ and a significant relationship $(p=0.02)$ was found between good knowledge and practice scores using Pearson's correlation coefficient (Table 5).

\section{Discussion}

The transmission of COVID-19 poses a risk for people who come in close contact with an infected individual, and the risk is greater among those who are in close proximity to or work near the patient, i.e., relatives and healthcare workers. The distance between the working field and the dentist is approx. $35-40 \mathrm{~cm}$, and certain procedures can be very time-consuming, which puts the dentist at a higher risk of contacting COVID-19.14,15

Table 4. Association between demographic variables and the participants'knowledge and practice scores using the multivariate linear regression analysis

\begin{tabular}{|c|c|c|c|c|c|}
\hline & Predictor & Coefficient & SD & $t$ & $p$-value \\
\hline \multirow{4}{*}{ Knowledge } & constant & 26.42 & 2.26 & 40.21 & 0.00 \\
\hline & qualifications & 2.23 & 3.19 & 2.60 & $0.04^{*}$ \\
\hline & years of practice & -1.02 & 0.52 & -0.99 & $0.02^{*}$ \\
\hline & location (continent of residence) & 2.32 & 0.43 & 6.21 & 0.55 \\
\hline \multirow{4}{*}{ Practice } & constant & 33.47 & 1.02 & 20.06 & 0.00 \\
\hline & qualifications & 1.23 & 1.14 & 4.30 & $0.03^{*}$ \\
\hline & years of practice & 5.21 & 2.12 & 2.11 & 1.62 \\
\hline & location (continent of residence) & -6.88 & 0.25 & 2.66 & 0.83 \\
\hline
\end{tabular}

* statistically significant $(p<0.05)$.

Table 5. Correlation between knowledge, attitudes and practices using Pearson's correlation test

\begin{tabular}{|c|c|c|c|c|}
\hline & ip between & Pearson's coefficient of correlation & $\mathrm{Cl}$ & $p$-value \\
\hline knowledge & practices & +0.669 & $0.77-26.64$ & $0.02^{*}$ \\
\hline
\end{tabular}

$\mathrm{Cl}$ - confidence interval; ${ }^{*}$ statistically significant $(p<0.05)$. 
To assess the preparedness of the healthcare worker to combat any disease outbreak, researchers across the globe try to assess their knowledge of the disease. The present knowledge scores regarding COVID-19 (92.7\%) are higher as compared to those presented by Gupta et al. (the Zika virus (ZIKV) pandemic; 38.2\% among Indian dentists), Fatiregun et al. (the swine influenza (H1N1) virus; 31\% among senior Nigerian healthcare workers), Aung et al. (the Ebola virus; $54.7 \%$ nursing students in Myanmar), Shivlingesh et al. (the influenza A (H1N1) outbreak; 52.6\% of the Indian population), and Singh et al. (the ZIKV outbreak; $61.7 \%$ among the students of a dental institute). ${ }^{16-20}$ An important aspect of this study is that responses were collected on a multinational scale, and such high knowledge scores are promising as far as the role of dentists in combating the COVID-19 outbreak is concerned.

In this context, recording properly the travel history of the patient prior to any treatment becomes paramount. In developing countries, purchasing extra PPE (gowns, gloves, etc.) and the cost of the fumigation/sterilizing of the dental clinic can impact the dental clinician financially; hence, incorporating the travel history can help significantly reduce the transmission as well as the burden of the disease. International travelling has sharply increased over the past few years due to declining air fares, easy accessibility, flexible timings, and an increasing number of airports, which in turn is contributing to traveler-associated infections (especially respiratory infections). ${ }^{21}$ In the present study, $96.2 \%$ of the dentists reported including the travel history while recording the history of the patient and this was important in a timely diagnosis, which could prevent further propagation of infection.

The initial source or information among the dentists was the Internet (37.7\%), followed by the social media (30.9\%), which is in agreement with the results obtained by Gupta et al., who reported that during the ZIKV pandemic, most of the knowledge gained by the dentists in the Tricity area in India, had its source in the Internet (37.8\%). ${ }^{16}$ During the development of a new strain of an infectious agent, there might not be enough data available in scholarly journals and/or textbooks, and hence, dentists might access trusted sites like the ones of the Centers of Disease Control and Prevention (CDC), WHO or the websites of health ministries of their respective countries for information. The use of the Internet however, is dependent on various factors like personal preferences, internet availability, type of device, speed, cost, etc. In contrast to this study, Fatiregun et al. reported television as the primary source of data (73.6\%) among senior healthcare workers in Nigeria during the influenza A (H1N1) pandemic. ${ }^{17}$

All dentists agreed that they could help spread awareness regarding the disease, and that hand hygiene and PPE were effective in preventing COVID-19. The threat of any epidemic makes all healthcare providers alerted, as they are at a high risk of contracting infection and it is the nature of their work to selflessly treat their patients.
As per the GeoSentinel surveillance survey, $11 \%$ of the respiratory tract infections were reported among the travelers returning to their country of residence, and PPE can provide protection as well as reduce the risk of any nosocomial infections and cross-transmission in the dental setting. ${ }^{22,23}$ Therefore, the risk to the healthcare worker is not only from external travelers, but also from their regular patients who travel on a regular basis, and this threat was acknowledged by the dentists who could correctly (with statistical significance) identify the system affected in COVID-19.

Alarmingly, only $43.8 \%$ of the dentists reported that their staff was sensitized as per the WHO guidelines for the prevention of COVID-19. This has to be addressed immediately and care should be taken to sensitize the auxiliary staff as per the current CDC and WHO guidelines to combat the spread of this disease.

A total of 825 (95.9\%) dentists responded that COVID-19 was fatal in nature and this could be attributed to the fact that the mortality associated with any new outbreak (although lower in the case of COVID-19) instills a fear of the unknown among people. These figures are on the higher end when compared to the responses of the healthcare providers assessing the fatality of the ZIKV (54.8\%) and $\mathrm{H} 1 \mathrm{~N} 1$ (51\%) pandemics. ${ }^{24,25}$ Since the responses of the present study were collected when COVID-19 was spreading to other nations, little was known about the characteristics of the virus and there was less information regarding the patients cured of COVID-19, the participating dentists might have assumed that COVID-19 had a high fatality ratio.

The outbreak of COVID-19 has shown a drastic effect on one's social life, since all mass gatherings and social events are being avoided to reduce the transmission rates. Apart from other preventive measures, significant differences are noticed between the continents regarding the number of people avoiding social gatherings.

It was observed that the dentists with higher qualifications (postgraduates) reported better and significant knowledge scores as compared to graduates. Various authors have documented similar findings during the ZIKV and Ebola hemorrhagic fever pandemics. ${ }^{16,26,27}$ The possible explanation might be that postgraduate studies involve performing some kind of research (thesis) and updating the dentist's knowledge based on recent guidelines and evidence-based practice. Contrary to our findings, Harapan et al. reported that general practitioners had a higher OR of having a good knowledge as compared to specialist doctors. ${ }^{28}$ This can be attributed to global disparities in the dental curriculum and attitudes of the dental faculty authorities toward motivation, encouragement, involvement, and providing assistance to undergraduates in any kind of research projects.

The study is prone to some limitations, one of them being the social desirability bias. In order to eliminate it, we did not ask for any personal information and assured 
the participants as to the confidentiality of their data. Secondly, due to the cross-sectional nature of the study and the employed sampling technique, the self-selection bias on the side of the respondents could have occurred. Since this questionnaire was designed to reach the global population of dentists, and due to geographical variations in the way English is spoken and comprehended across the world, inadvertently, there was a slight possibility that the dentists might have experienced the questionnaire bias while answering the questions. However, during the implementation of the pilot study itself, it was ensured that the questions were kept as neutral and simple as possible to avoid such kind of bias.

\section{Conclusions}

In the present study, dentists were found to obtain good knowledge and practice scores, which is important to combat COVID-19. Dentists should appropriately use the social media to spread awareness among people, and in their clinical practice, they should screen, isolate and refer the potential cases having the symptoms of COVID-19. They are also advised to follow the CDC and WHO guidelines in their clinics, and sensitize their staff so that no stone is left unturned in defeating this pandemic.

\section{ORCID iDs}

Shivalingesh Krishnappa Kamate (1) https://orcid.org/0000-0002-4636-522X Swati Sharma (1) https://orcid.org/0000-0001-7181-5299

Sahil Thakar (1) https://orcid.org/0000-0002-8686-5309

Divya Srivastava (1) https://orcid.org/0000-0002-1755-8436

Kaushikee Sengupta (1) https://orcid.org/0000-0002-0086-8323

Ahmed Jhurry Hadi (1) https://orcid.org/0000-0001-8491-7032

Alankrita Chaudhary (1) https://orcid.org/0000-0003-2086-6779

Ruby Joshi (1) https://orcid.org/0000-0002-2816-9591

Kuldeep Dhanker (1D) https://orcid.org/0000-0002-5783-7229

\section{References}

1. Li Y, Xia L. Coronavirus Disease 2019 (COVID-19): Role of chest CT in diagnosis and management [Epub ahead of print]. AJR Am J Roentgenol. 2020:1-7.

2. Gorbalenya AE, Enjuanes L, Ziebuhr J, Snijder EJ. Nidovirales: Evolving the largest RNA virus genome. Virus Res. 2006;117(1):17-37.

3. Peng $X, X u X$, Li Y, Cheng L, Zhou X, Ren B. Transmission routes of $2019-\mathrm{nCoV}$ and controls in dental practice. Int J Oral Sci. 2020;12(1):9.

4. Fan Y, Zhao K, Shi ZL, Zhou P. Bat coronaviruses in China. Viruses. 2019;11(3):210

5. Fehr AR, Perlman S. Coronaviruses: An overview of their replication and pathogenesis. Methods Mol Biol. 2015;1282:1-23.

6. Huang C, Wang Y, Li X, et al. Clinical features of patients infected with 2019 novel coronavirus in Wuhan, China. Lancet. 2020;395(10223):497-506.

7. Wang, D, Hu B, Hu C, et al. Clinical characteristics of 138 hospitalized patients with 2019 novel coronavirus-infected pneumonia in Wuhan, China [Epub ahead of print]. JAMA. 2020.

8. Chen N, Zhou M, Dong X, et al. Epidemiological and clinical characteristics of 99 cases of 2019 novel coronavirus pneumonia in Wuhan, China: A descriptive study. Lancet. 2020;395(10223):507-513.

9. Chowell $G$, Abdirizak $F$, Lee $S$, et al. Transmission characteristics of MERS and SARS in the healthcare setting: A comparative study. BMC Med. 2015;13:210.
10. Bin SY, Heo JY, Song MS, et al. Environmental contamination and viral shedding in MERS patients during MERS-CoV outbreak in South Korea. Clin Infect Dis. 2016;62(6):755-760.

11. Ong SWX, Tan YK, Chia PY, et al. Air, surface environmental, and personal protective equipment contamination by severe acute respiratory syndrome coronavirus 2 (SARS-CoV-2) from a symptomatic patient [Epub ahead of print]. JAMA. 2020.

12. Dhama K, Patthi B, Singla A, et al. Global tourist guide to oral care - a systematic review. J Clin Diagn Res. 2016;10(9):ZE01-ZE04.

13. IBM Corp. Released 2012. IBM SPSS Statistics for Windows, Version 21.0. Armonk, NY: IBM Corp.

14. Pîrvu C, Pătraşcu I, Pîrvu D, lonescu C. The dentist's operating posture - ergonomic aspects. J Med Life. 2014;7(2):177-182.

15. Meng L. Hua F, Bian Z. Coronavirus Disease 2019 (COVID-19): Emerging and future challenges for dental and oral medicine [Epub ahead of print]. J Dent Res. 2020.

16. Gupta N, Randhawa RK, Thakar S, Bansal M, Gupta P, Arora V. Knowledge regarding Zika virus infection among dental practitioners of Tricity area (Chandigarh, Panchkula and Mohali), India. Niger Postgrad Med J. 2016;23(1):33-37.

17. Fatiregun AA, Olowookere SA, Oyebade AO. Pandemic influenza A (H1N1): Knowledge among senior health workers at a secondary health care institution in Southwest, Nigeria. Afr Health Sci. 2011;11(2):171-175.

18. Aung MH, Oo WM, Lynn KK, Mya KM. Knowledge and perception towards Ebola virus disease among nursing students in the University of Nursing, Yangon. Myanmar Med J. 2015;57(3):8-14.

19. Shivlingesh KK, Agrawal A, Chaudhary H, Singh K, Mishra P, Asawa K. Public knowledge, attitude and behavioural changes in an Indian population during the Influenza A (H1N1) outbreak. J Infect Dev Ctries. 2010;4(1):7-14.

20. Singh M, Singh K, Puri MS, et al. Knowledge and perception towards Zika outbreak in a dental institute. Dentistry. 2017;7(3):1000420.

21. Duong TN, Waldman SE. Importance of a travel history in evaluation of respiratory infections. Curr Emerg Hosp Med Rep. 2016;4(3):141-152.

22. Fotedar S, Sharma KR, Bhardwaj V, Fotedar V. Precautions in dentistry against swine flu. SRM J Res Dent Sci. 2013;4(4):161-163.

23. Leder $\mathrm{K}$, Torresi J, Libman MD, et al. GeoSentinel surveillance of illness in returned travelers, 2007-2011. Ann Intern Med. 2013;158(6):456-468.

24. Alessa M, Alzahrani M, Alshehri A, et al. Knowledge regarding Zika virus infection among healthcare providers in an academic tertiary care center in Riyadh, Saudi Arabia: A cross-sectional survey study. Can J Infect Dis Med Microbiol. 2020:2020:8145219.

25. Savas E, Tanriverdi D. Knowledge, attitudes and anxiety towards influenza $\mathrm{A} / \mathrm{H} 1 \mathrm{~N} 1$ vaccination of healthcare workers in Turkey. BMC Infect Dis. 2010;10:281.

26. Gupta N, Mehta N, Gupta P, Arora V, Setia P. Knowledge regarding Ebola Hemorrhagic Fever among private dental practitioners in Tricity, India: A cross-sectional questionnaire study. Niger Med J. 2015;56(2):138-142.

27. Holakouie-Naieni $K$, Ahmadvand A, Raza O, et al. Assessing the knowledge, attitudes, and practices of students regarding Ebola virus disease outbreak. Iran J Public Health. 2015;44(12):1670-1676.

28. Harapan H, Aletta A, Anwar S, et al. Healthcare workers' knowledge towards Zika virus infection in Indonesia: A survey in Aceh. Asian Pac J Trop Med. 2017;10(2):189-194. 